\title{
Produção de fitomassa e acúmulo e liberação de nutrientes por plantas de cobertura na safrinha
}

\author{
Leandro Pereira Pacheco(1), Wilson Mozena Leandro(2), Pedro Luiz Oliveira de Almeida Machado(3), \\ Renato Lara de Assis ${ }^{(4)}$, Tarcísio Cobucci ${ }^{(3)}$, Beáta Emoke Madari( ${ }^{(3)}$ e Fabiano André Petter ${ }^{(1)}$
}

\begin{abstract}
(1)Universidade Federal do Piauí, Departamento de Agronomia, Campus Prof. Cinobelina Elvas, Rodovia BR 135, Km 03, CEP 74900-000 Bom Jesus, PI. E-mail: leandroppacheco@terra.com.br, fabianopetter@brturbo.com.br (2)Universidade Federal de Goiás, Departamento de Solos, Rodovia Goiânia-Nova Veneza, Km 0, Campus II, CEP 74001-970 Goiânia, GO. E-mail: mozena@bol.com.br ${ }^{(3)}$ Embrapa Arroz e Feijão, Caixa Postal 179, CEP 75375-000 Santo Antônio de Goiás, GO. E-mail: pmachado@cnpaf.embrapa.br, cobucci@cnpaf.embrapa.br, madari@cnpaf.embrapa.br ${ }^{(4)}$ Instituto Federal Goiano, Campus Iporá, Rodovia GO 060, Km 1, Zona Rural, CEP $76200-000$ Iporá, GO. E-mail: relassis@bol.com.br
\end{abstract}

Resumo - O objetivo deste trabalho foi avaliar o desempenho de plantas de cobertura quanto à fitomassa, ao acúmulo e à liberação de nutrientes, durante a entressafra, em um Latossolo Vermelho distroférrico, no Cerrado. O experimento foi realizado em Santo Antônio de Goiás e Rio Verde, GO, de novembro de 2007 a outubro de 2008. O delineamento experimental foi o de blocos ao acaso, em esquema de parcelas subdivididas no tempo, com as plantas de cobertura avaliadas nas parcelas principais e com os períodos de coleta de fitomassa nas subparcelas, com quatro repetições. As espécies avaliadas foram: Urochloa brizantha, U. ruziziensis, Pennisetum glaucum e U. ruziziensis + Cajanus cajan e, como referência, pousio com vegetação espontânea. As épocas de coleta foram seis em Santo Antônio de Goiás e cinco em Rio Verde, a partir da data de dessecação do P. glaucum, aos 60 dias após a semeadura. O P. glaucum apresentou as maiores quantidades de fitomassa seca no início da entressafra, enquanto as outras coberturas apresentaram acúmulos significativos de fitomassa e nutrientes no final da entressafra.

Termos para indexação: Braquiária, decomposição, feijão-guandu, integração lavoura-pecuária, milheto, plantio direto.

\section{Biomass production and nutrient accumulation and release by cover crops in the off-season}

\begin{abstract}
The objective of this work was to evaluate the performance of cover crops regarding biomass production and nutrient accumulation and release during the off-season in a clayey Red Latossol (Ferralsol) in the Cerrado. The assay was carried out at Santo Antônio de Goiás and Rio Verde, GO, Brazil from November/2007 to October/2008. A randomized block design in a split-plot arrangement in time was used, with the cover crops evaluated in the main plot and with biomass sampling time in the subplot, with four replicates. The evaluated species were: Urochloa brizantha, U. ruziziensis, Pennisetum glaucum e U. ruziziensis + Cajanus cajan and, as reference, a fallow treatment with spontaneous vegetation. Sampling times were six in Santo Antônio de Goiás and five in Rio Verde, since the desiccation date of $P$. glaucum, 60 days after cover crop sowing. P. glaucum showed the largest quantities of dry biomass at the beginning of the off-season, while the other covers showed significant accumulations of biomass and nutrients at the end of the off-season.
\end{abstract}

Index terms: Brachiaria, decomposition, guandu bean, crop-livestock integration, milllet, no-tillage.

\section{Introdução}

A região do Cerrado destaca-se na produção de grãos, com mais de $50 \%$ da produção de soja e milho do Brasil (Companhia Nacional de Abastecimento, 2009), o que tem despertado a preocupação quanto ao uso de práticas conservacionistas do solo (Prior et al., 2004). A entressafra, no outono e inverno, entre os meses de abril e setembro, é uma época com reduzidas precipitações e elevada temperatura, o que dificulta o estabelecimento de plantas de cobertura (Pacheco et al., 2008). Em algumas regiões do Cerrado, no período da safrinha, logo após a colheita das culturas de verão, de fevereiro a abril, há possibilidade de semeadura de espécies com crescimento rápido e resistência ao estresse hídrico. 
As plantas de cobertura semeadas na entressafra, em sistema de plantio direto, apresentam capacidade de absorver nutrientes em camadas subsuperficiais e, depois, de liberá-los nas camadas superficiais por meio da decomposição e da mineralização dos seus resíduos (Torres et al., 2008), o que pode contribuir para o uso eficiente de fertilizantes nas culturas anuais em sucessão. Essas espécies auxiliam na conservação dos solos, pela maior agregação das partículas e pela proteção da superfície do solo ao impacto direto das chuvas.

A elevada taxa de decomposição dos resíduos vegetais após o manejo tem dificultado a manutenção da fitomassa na superfície do solo (Boer et al., 2007; Torres et al., 2008). As plantas de cobertura devem apresentar alta capacidade de produção de fitomassa e, sobretudo, elevada resistência quanto à decomposição, que se relaciona à proporção entre carbono e nitrogênio (Crusciol et al., 2005) ou ao nível de recalcitrância dos resíduos (Giacomini et al., 2003). Carpim et al. (2008) destacam que o estádio de florescimento é o momento ideal para o manejo das plantas de cobertura, em razão do maior acúmulo de fitomassa e nutrientes.

O milheto (Pennisetum glaucum) é uma espécie bastante utilizada na entressafra, por causa de seu crescimento rápido, elevada produção de fitomassa e ciclagem de nutrientes, mesmo em condições de deficit hídrico. Segundo Boer et al. (2007), no Cerrado goiano, a cultivar ADR 300, semeada em abril, alcança o estádio de florescimento aos 60 dias após a emergência, com produção de fitomassa seca superior a $10.000 \mathrm{~kg} \mathrm{ha}^{-1}$ e capacidade de acúmulo de mais de $400 \mathrm{~kg} \mathrm{ha}^{-1}$ de potássio em sua parte aérea. Torres et al. (2005) observaram no Cerrado do triângulo mineiro, que o P. glaucum foi capaz de acumular mais de $150 \mathrm{~kg} \mathrm{ha}^{-1}$ e $50 \mathrm{~kg} \mathrm{ha}^{-1}$ de nitrogênio quando semeado em outubro e março, respectivamente.

O uso de plantas de cobertura com hábito perene, capazes de suportar o estresse hídrico e altas temperaturas durante o inverno e a primavera no Cerrado, como as braquiárias (Urochloa brizantha e U. ruziziensis), podem proporcionar significativo acúmulo de fitomassa e retardar o início de sua decomposição em relação ao milheto (Pacheco et al., 2008). Em estudos de Torres et al. (2005), a $U$. brizantha, semeada no final de março e dessecada aos 110 dias, não se destacou na produção de fitomassa e no acúmulo de nitrogênio, com $2.100 \mathrm{~kg} \mathrm{ha}^{-1} \mathrm{e} 41 \mathrm{~kg} \mathrm{ha}^{-1}$, respectivamente. Apesar do crescimento inicial dessa espécie ser lento (Portes et al., 2000), seu hábito perene possibilita a retomada de crescimento após o início das chuvas de primaveraverão, em setembro, o que pode proporcionar aumento no acúmulo de fitomassa seca superior à $11.000 \mathrm{~kg} \mathrm{ha}^{-1}$ (Timossi et al., 2007).

A consorciação de espécies do gênero Urochloa com leguminosas semiperenes, como o feijão-guandu (Cajanus cajan), pode significar incremento de fitomassa (Amabile et al., 2000) e nitrogênio no solo via fixação biológica (Henriksen et al., 2002). No estudo de Torres et al. (2005), o C. cajan alcançou $62 \mathrm{~kg} \mathrm{ha}^{-1}$ de nitrogênio em sua fitomassa, aos 110 dias após a semeadura em safrinha. Gama-Rodrigues et al. (2007) mostraram que a introdução de leguminosas como plantas de cobertura elevou a qualidade de resíduos, em razão do maior suprimento de nitrogênio, fósforo e cálcio ao solo. Contudo, ainda são necessários estudos que avaliem os potenciais do consórcio entre espécies do gênero Urochloa e leguminosas perenes para a produção de fitomassa e para o acúmulo de nutrientes que possam ser aproveitados pelas culturas anuais semeadas em sucessão no Cerrado.

O objetivo deste trabalho foi avaliar o desempenho de plantas de cobertura do solo quanto à fitomassa, ao acúmulo e à liberação de nutrientes, durante a entressafra, em um Latossolo Vermelho distroférrico, no Cerrado.

\section{Material e Métodos}

Foram realizados dois experimentos. O experimento 1 foi instalado em Santo Antônio de Goiás, GO, na Embrapa Arroz e Feijão, Fazenda Capivara $\left(16^{\circ} 28^{\prime} 00^{\prime \prime} \mathrm{S}\right.$ e $49^{\circ} 17^{\prime} 00^{\prime \prime} \mathrm{W}$, a $823 \mathrm{~m}$ de altitude), de novembro de 2007 a outubro de 2008, em um Latossolo Vermelho distroférrico (Santos et al., 2006), com as seguintes características na camada de 0-20 cm: 549, $106 \mathrm{e}$ $345 \mathrm{~g} \mathrm{~kg}^{-1}$ de argila, silte e areia, respectivamente; $\mathrm{pH}$ $\left(\mathrm{CaCl}_{2}\right)$ 5,2; P (Mehlich 1), 6,3 mg kg-1; K, 0,2 cmol $_{\mathrm{c}}$ $\mathrm{dm}^{-3} ; \mathrm{Ca}, 2,4 \mathrm{cmol}_{\mathrm{c}} \mathrm{dm}^{-3} ; \mathrm{Mg}, 0,7 \mathrm{cmol}_{\mathrm{c}} \mathrm{dm}^{-3} ; \mathrm{H}+\mathrm{Al}$, $4,2 \mathrm{cmol}_{\mathrm{c}} \mathrm{dm}^{-3}$; matéria orgânica, $24 \mathrm{~g} \mathrm{~kg}^{-1}$; capacidade de troca de cátions, 7,6 $\mathrm{cmol}_{\mathrm{c}} \mathrm{dm}^{-3}$ e saturação por bases, 44\%. O clima da localidade de estudo, conforme classificação de Köppen, é do tipo Cwa. As precipitações ocorridas durante a condução dos experimentos estão na Figura 1.

A área foi cultivada com rotação soja-pousio em sistema de plantio direto na safra 2005/2006 e pousio-pousio em 2006/2007. A colheita da soja safra 2007/2008 ocorreu no dia 22 de março, e, no dia 25 
de março, realizou-se a semeadura das plantas de cobertura, em blocos ao acaso, em esquema de parcelas subdividas, com quatro repetições. As parcelas foram constituídas por quatro espécies de plantas de cobertura e pousio: $U$. ruziziensis $\left(10 \mathrm{~kg} \mathrm{ha}^{-1}\right.$ de sementes com valor cultural - VC de 70\%), U. brizantha $\left(10 \mathrm{~kg} \mathrm{ha}^{-1}\right.$, VC de 70\%), P. glaucum (milheto ADR 300, com $\left.13 \mathrm{~kg} \mathrm{ha}^{-1}\right)$, U. ruziziensis + C. cajan $\left(5 \mathrm{~kg} \mathrm{ha}^{-1}+\right.$ $10 \mathrm{~kg} \mathrm{ha}^{-1}$, respectivamente) e pousio (vegetação espontânea, com predominância de trapoeraba Commelina benghalensis, buva - Conyza bonariensis e picão-preto - Bidens pilosa). As plantas de cobertura foram semeadas com semeadora-adubadora de plantio direto, com espaçamento entre linhas de $25 \mathrm{~cm}$, sem
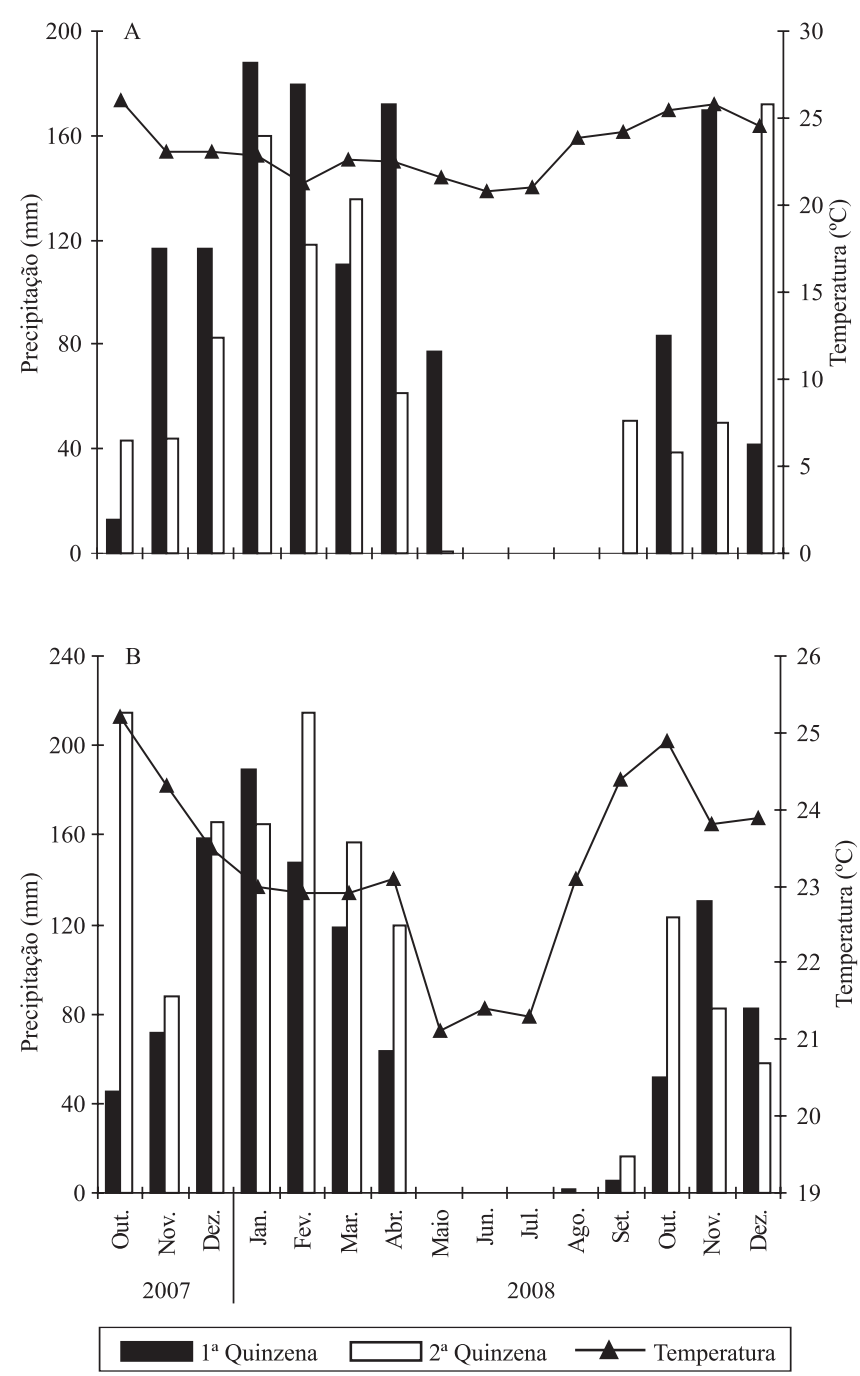

Figura 1. Precipitação $(\mathrm{mm})$ e temperatura média $\left({ }^{\circ} \mathrm{C}\right)$ em Santo Antônio de Goiás, GO (A), e Rio Verde, GO (B), durante a condução dos experimentos. uso de fertilizantes. A área de cada parcela era de $8 \times 16 \mathrm{~m}$. As parcelas foram subdivididas no tempo, com cinco épocas de avaliação: $0,15,30,60,120$ e 140 dias a partir da data de dessecação do P. glaucum, com uso do herbicida glifosato (1.468 $\mathrm{g} \mathrm{ha}^{-1}$ de i.a.), na ocasião do seu florescimento, em 22/5/2008, o que correspondeu a $60,75,90,120,180$ e 200 dias após a semeadura das plantas de cobertura. A última avaliação, aos 200 dias, coincidiu com o momento de dessecação para a semeadura da próxima safra, 2008/2009, em outubro de 2008. As outras plantas de cobertura não foram dessecadas na entressafra, por não terem atingido o florescimento e apresentarem hábito perene, embora, as épocas de suas avaliações tenham se iniciado no momento da dessecação do $P$. glaucum, para possibilitar a comparação de comportamento entre as espécies estudadas. A dessecação de manejo dessas espécies ocorreu apenas em outubro de 2008, imediatamente depois da última avaliação, aos 200 dias após sua semeadura.

Foi avaliada a fitomassa seca (FS) das plantas de cobertura em todas as subparcelas, segundo método proposto por Crusciol et al. (2005), com uso de quadrado de ferro (gabarito de $0,25 \mathrm{~m}^{2}$ ), com duas repetições por subparcela. Em seguida, as amostras foram submetidas à secagem em estufa com temperatura entre 65 e $75^{\circ} \mathrm{C}$, por 72 horas e pesadas para obtenção da FS. Os resíduos foram triturados em moinho tipo Willey (malha de $2 \mathrm{~mm}$ ), para posterior determinação das concentrações de $\mathrm{N}, \mathrm{P}, \mathrm{K}, \mathrm{Ca}$ e $\mathrm{Mg}$, com os métodos sugeridos por Nogueira et al. (2005). Para a determinação da relação $\mathrm{C} / \mathrm{N}$, a concentração de carbono total nos tecidos vegetais foi quantificada por método colorimétrico (Cantarella et al., 2001).

Para descrever a decomposição de fitomassa e a liberação de nutrientes no $P$. glaucum, depois da dessecação aos 60 dias após a semeadura (DAS), os dados foram ajustados a um modelo exponencial decrescente, descrito por Wieder \& Lang (1982): $\mathrm{P}_{\mathrm{L}}=$ Po $\exp (-\mathrm{kt})$, em que $\mathrm{P}_{\mathrm{L}}$ é a quantidade de fitomassa e nutrientes existentes no tempo $\left(\mathrm{kg} \mathrm{ha}^{-1}\right)$; Po é a fração de fitomassa e nutrientes potencialmente liberados $\left(\mathrm{kg} \mathrm{ha}^{-1}\right)$; e k é a taxa de liberação dos nutrientes $\left(\mathrm{g} \mathrm{g}^{-1}\right)$. Com o valor de $\mathrm{k}$, foi calculado o tempo de meia-vida ( $\mathrm{T}^{1} 1 / 2$ vida) da fitomassa e dos nutrientes remanescentes do $P$. glaucum, com a fórmula $\mathrm{T}^{1} / 2$ vida $=0,693 / \mathrm{k}$, proposta por Paul \& Clark (1989). A equação polinomial linear foi utilizada para descrever o acúmulo 
de fitomassa e nutrientes: $\mathrm{P}_{\mathrm{a}}=$ Po + ax, em que $\mathrm{P}_{\mathrm{a}}$ é a quantidade de fitomassa e nutrientes existentes no tempo $\mathrm{x}\left(\mathrm{kg} \mathrm{ha}^{-1}\right)$, e a é taxa de acúmulo diária de fitomassa e nutrientes (kg por dia).

Os resultados foram submetidos à análise de variância e as médias comparadas pelo teste de Tukey, a 5\% de probabilidade. As equações de regressão foram obtidas com auxílio do programa Sigma Plot, versão 7.0.

O experimento 2 foi instalado em Rio Verde, GO, no Centro Tecnológico da Cooperativa Mista dos Produtores Rurais do Sudoeste Goiano (17047'30"S e $50^{\circ} 57^{\prime} 44^{\prime \prime} \mathrm{W}$, a $770 \mathrm{~m}$ de altitude), de dezembro de 2007 a outubro de 2008, em um Latossolo Vermelho distroférrico (Santos et al., 2006), com as seguintes características na camada de $0-20 \mathrm{~cm}: 420 ; 110$; $470 \mathrm{~g} \mathrm{~kg}^{-1}$ de argila, silte e areia, respectivamente; $\mathrm{pH}$ $\left(\mathrm{CaCl}_{2}\right)$ 4,8; P (Mehlich 1), 4,2 $\mathrm{mg} \mathrm{kg}^{-1} ; \mathrm{K}, 0,14 \mathrm{cmol}_{\mathrm{c}}$ $\mathrm{dm}^{-3} ; \mathrm{Ca}, 1,9 \mathrm{cmol}_{\mathrm{c}} \mathrm{dm}^{-3} ; \mathrm{Mg}, \quad 0,4 \mathrm{cmol}_{\mathrm{c}} \mathrm{dm}^{-3}$; $\mathrm{H}+\mathrm{Al}, 4,7 \mathrm{cmol}_{\mathrm{c}} \mathrm{dm}^{-3}$; matéria orgânica, $29 \mathrm{~g} \mathrm{~kg}^{-1}$; capacidade de troca de cátions, $7,1 \mathrm{cmol}_{\mathrm{c}} \mathrm{dm}^{-3} \mathrm{e}$ saturação por bases, $32 \%$. O clima da localidade de estudo, conforme classificação de Köppen, é do tipo Cwa. As precipitações ocorridas durante a condução dos experimentos estão na Figura 1.

Nas duas safras anteriores, 2005/2006 e 2006/2007, a área foi cultivada com soja, no verão, e milheto, na safrinha, em sistema de plantio direto. A colheita da soja da safra 2007/2008 ocorreu no dia 9 de abril, e em 10 de abril de 2008, foram semeadas as mesmas espécies de plantas de cobertura do experimento 1, exceto a $U$. brizantha, com delineamento em blocos ao acaso, em esquema de parcelas subdivididas no tempo, com quatro repetições. Nas parcelas, foram testadas as plantas de cobertura, semeadas manualmente, com espaçamento entre linhas de $50 \mathrm{~cm}$, sem uso de fertilizantes. No tratamento pousio, houve predominância de capim-timbete (Cenchrus echinatus).
A área de cada parcela era de $5 \times 10 \mathrm{~m}$. Nas subparcelas, foram avaliadas cinco épocas de coletas de fitomassas: $0,15,30,60$ e 120 dias a partir da data de dessecação do $P$. glaucum na ocasião do seu florescimento, em $12 / 6 / 2008$, o que correspondeu a $60,75,90,120$ e 180 dias após a semeadura das plantas de cobertura.

As avaliações e os métodos de coleta e análise foram realizados como descrito no experimento 1 .

\section{Resultados e Discussão}

As plantas de cobertura apresentaram efeitos significativos quanto à produção de fitomassa e aos teores de N e P, em Santo Antônio de Goiás, e Ca e Mg em Rio Verde, o que demonstra a contribuição das plantas de cobertura na produção de palhada e ciclagem de nutrientes (Tabela 1). O P. glaucum se destacou na produção de FS aos 60 DAS com produções superiores a $8.000 \mathrm{~kg} \mathrm{ha}^{-1}$, em Santo Antônio de Goiás, e $3.600 \mathrm{~kg} \mathrm{ha}^{-1}$, em Rio Verde (Tabela 2). Resultados semelhantes foram encontrados por Crusciol \& Sorato (2007), Timossi et al. (2007) e Pires et al. (2008), com produções próximas de $9.000 \mathrm{~kg} \mathrm{ha}^{-1}$. A espécie apresentou elevado crescimento durante a safrinha, por causa de sua rápida emergência, estabelecimento e do acúmulo de fitomassa com as chuvas finais de verão.

A partir de 90 DAS, as espécies de Urochloa superaram os resíduos culturais remanescentes da dessecação do milheto aos 60 DAS, e alcançaram a produção de FS de $11.405 \mathrm{~kg} \mathrm{ha}^{-1}$ de U. brizantha, em Santo Antônio de Goiás, e $6.227 \mathrm{~kg} \mathrm{ha}^{-1}$ de U. ruziziensis em Rio Verde, no final do período de entressafra (200 e 180 DAS, respectivamente). Esses resultados estão de acordo com Timossi et al. (2007) que obtiveram produção de $11.000 \mathrm{~kg} \mathrm{ha}^{-1}$ de FS de U. brizantha no final do período de entressafra. Segundo Portes et al. (2000), as espécies de Urochloa apresentam significativo acúmulo

Tabela 1. Análise de variância (valores de F) para fitomassa e nutrientes, em Santo Antônio de Goiás, GO, e Rio Verde, GO.

\begin{tabular}{|c|c|c|c|c|c|c|c|}
\hline Fonte de variação & Fitomassa & $\mathrm{C} / \mathrm{N}$ & $\mathrm{N}$ & $\mathrm{P}$ & $\mathrm{K}$ & $\mathrm{Ca}$ & $\mathrm{Mg}$ \\
\hline & \multicolumn{7}{|c|}{ Santo Antônio de Goiás, GO } \\
\hline Plantas de cobertura & $219,55^{* *}$ & $59,14 * *$ & $295,66^{* *}$ & $228,85^{* *}$ & $173,19 * *$ & $68,30^{* *}$ & $89,32 * *$ \\
\hline Época de amostragem & $56,82 * *$ & $68,95 * *$ & $37,73 * *$ & $29,08 * *$ & $41,35 * *$ & $97,05 * *$ & $3,58 *$ \\
\hline \multirow[t]{2}{*}{ Plantas de cobertura $\mathrm{x}$ época } & $34,96 * *$ & $6,86^{* *}$ & $38,44 * *$ & $47,01 * *$ & $40,85 * *$ & $43,49 * *$ & $37,61 * *$ \\
\hline & \multicolumn{7}{|c|}{ Rio Verde, GO } \\
\hline Plantas de cobertura & $23,47 * *$ & $83,44 * *$ & $29,15^{* *}$ & $11,28 * *$ & $66,14 * *$ & $252,34 * *$ & $156,72 * *$ \\
\hline Época de amostragem & $72,43 * *$ & $128,86^{* *}$ & $18,35^{* *}$ & $27,70 * *$ & $79,29 * *$ & $366,45^{* *}$ & $92,91 * *$ \\
\hline Plantas de cobertura $\mathrm{x}$ época & $49,53 * *$ & $8,18^{* *}$ & $33,02 * *$ & $44,44 * *$ & $132,67 * *$ & $174,55 * *$ & $106,60 * *$ \\
\hline
\end{tabular}

* e **Significativo a 5 e $1 \%$ de probabilidade. 
de fitomassa a partir de 45 DAS, o que, associado ao hábito perene da espécie (Pacheco et al., 2008), a torna alternativa viável para a produção de fitomassa na entressafra. A $U$. brizantha apresentou maior potencial de crescimento na estação seca em comparação à U. ruziziensis em Santo Antônio de Goiás, em razão de sua elevada tolerância ao estresse hídrico, o que corrobora os resultados de Timossi et al. (2007).

Em Santo Antônio de Goiás, o pousio apresentou as menores médias de fitomassa em quase todas as épocas, em virtude do baixo crescimento vegetativo da comunidade infestante. Em Rio Verde, a produção de FS do pousio foi inferior à da $U$. ruziziensis aos 180 DAS e superior à fitomassa remanescente do $P$. glaucum, por causa da infestação de C. echinatus (capim-timbete) na área. $\mathrm{O}$ uso de pousio na região dos Cerrados tem sido conduta bastante comum na agricultura, o que pode resultar em quantidades insatisfatórias de fitomassa para um manejo conservacionista do solo, bem como dificultar o manejo de plantas daninhas durante o ciclo de crescimento das culturas anuais (Pires et al., 2008).

As menores FS foram encontradas em Rio Verde e ocorreram em decorrência da semeadura tardia e da baixa disponibilidade hídrica, que prejudicaram o crescimento das espécies de plantas de cobertura (Tabela 2). Esses resultados são concordantes com os de Torres et al. (2005) que obtiveram $3.600 \mathrm{~kg} \mathrm{ha}^{-1} \mathrm{de}$ FS de $P$. glaucum, cultivado na região do Cerrado do triângulo mineiro, no final do mês de maio, com baixo índice pluvial no período após a semeadura.

Quanto à decomposição $\left(\mathrm{P}_{\mathrm{L}}\right)$ dos resíduos culturais, após dessecação do P. glaucum, em Santo Antônio de Goiás e Rio Verde (Tabela 2), o tempo de meia vida ( $\mathrm{T}^{1 / 2}$ vida) foi de 95 e 83 dias, respectivamente, inferiores aos resultados apresentados por Torres et al. (2008) na região do Cerrado (T $1 / 2$ vida de 115 dias). Essa diferença está associada às variações climáticas de cada região de estudo (Boer et al., 2007) e ao uso de cultivares com potenciais distintos na produção de frações de resíduos menos sensíveis aos agentes decompositores (Giacomini et al., 2003). A U. brizantha e a U. ruziziensis $+C$. cajan, em Santo Antônio de Goiás, bem como a $U$. ruziziensis e a U. ruzizensis $+C$. cajan, em Rio Verde, apresentaram acúmulo linear de FS, o que contribuiu para que essas espécies superassem o P. glaucum, aos 200 e 180 DAS, respectivamente. A elevada resistência ao estresse hídrico e a rebrota dessas espécies após o reinício das chuvas contribuíram para o aumento de FS durante a entressafra, com possibilidade de se realizar a semeadura das culturas anuais em plantio direto com satisfatória presença de palhada sobre o solo. A redução significativa da fitomassa aos 180 DAS ocorreu em razão do elevado estresse hídrico na época, em agosto, o que provocou senescência parcial dos tecidos das plantas de cobertura.

Tabela 2. Fitomassa seca (FS, $\mathrm{kg} \mathrm{ha}^{-1}$ ) das plantas de cobertura (Urochloa ruziziensis, U. brizantha, Pennisetum glaucum e U. ruziziensis + Cajanus cajans), semeadas após a colheita da soja na safra 2007/2008 e avaliadas em cinco épocas em Santo Antônio de Goiás, GO, e Rio Verde, GO ${ }^{(1)}$.

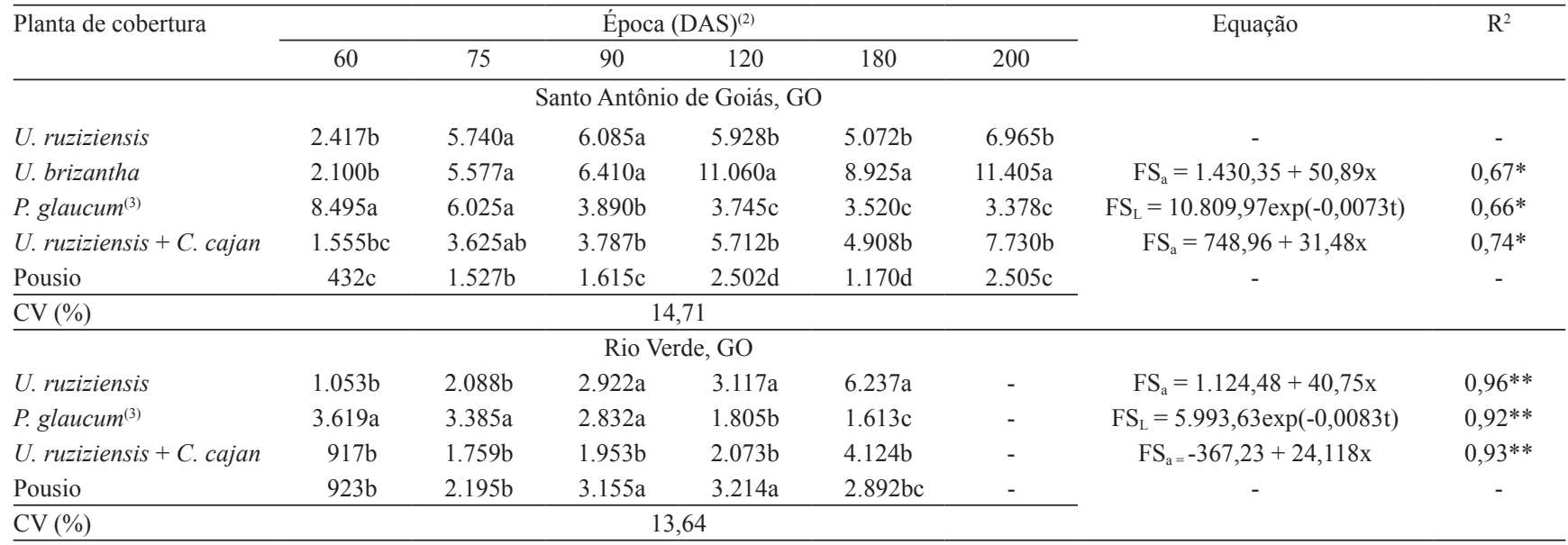

${ }^{(1)}$ Médias seguidas de letras iguais, nas colunas, não diferem entre si pelo teste de Tukey, a 5\% de probabilidade. ${ }^{(2)} \mathrm{DAS}$, dias após a semeadura das plantas de cobertura em Santo Antônio de Goiás, GO, 25/3/2008, e Rio Verde, GO, 10/4/2008. ${ }^{(3)}$ Dia da dessecação do P. glaucum no florescimento em Santo Antônio de Goiás, GO, 22/5/2008, e Rio Verde, GO, 12/6/2008. * e **Significativo a 5 e $1 \%$ de probabilidade, respectivamente. 
No acúmulo $\left(\mathrm{P}_{\mathrm{a}}\right)$ e na liberação $\left(\mathrm{P}_{\mathrm{L}}\right)$ de nutrientes, o P. glaucum apresentou os maiores valores de relação $\mathrm{C} / \mathrm{N}$ em todas as épocas e locais de avaliações, o que pode ser explicado pela sua elevada taxa de crescimento, que permitiu que atingisse o estádio de florescimento aos 60 DAS, e que se iniciasse a decomposição dos resíduos após a dessecação de manejo (Tabelas 3 e 4). Carpim et al. (2008) encontraram valores distintos de relação $\mathrm{C} / \mathrm{N}$ de 18,19 e 22:1 para o $P$. glaucum cultivar ADR 300 no Cerrado do sudoeste goiano, nos estádios fenológicos de pré-emborrachamento, pré-florescimento e início de florescimento.

Em Santo Antônio de Goiás, entre as espécies de Urochloa, a U. brizantha apresentou maior relação $\mathrm{C} / \mathrm{N}$ aos $200 \mathrm{DAS}$, em virtude da menor capacidade de rebrota e da elevada presença de colmos em processo de senêscencia. A U. ruziziensis e o consórcio U. ruziziensis + C. cajan apresentaram menor relação $\mathrm{C} / \mathrm{N}$ nos dois experimentos, ao final do período de entressafra, o que pode favorecer a liberação mais rápida de nutrientes ao solo após sua dessecação, para semeadura das culturas anuais em rotação. Esses resultados são explicados pelo elevado índice de rebrota e pela proporção entre folhas e colmos dessas espécies após as chuvas iniciais de verão, e também, pelo elevado teor de nitrogênio da leguminosa $C$. cajan.

Em Rio Verde, a elevada relação $\mathrm{C} / \mathrm{N}$ no pousio aos 90 , 120 e 180 DAS resultou da presença de resíduos culturais de C. echinatus, com significativa proporção de caules em processo de decomposição, oriundos da senescência de plantas observadas durante a entressafra.

No acúmulo de N, P, K, Ca e Mg, o P. glaucum destacou-se aos 60 DAS, em Santo Antônio de Goiás e Rio Verde (Tabelas 3 e 4). Quanto ao N, resultados semelhantes foram observados por Torres et al. (2005) e Boer et al. (2007) na região do Cerrado (55 e $121 \mathrm{~kg} \mathrm{ha}^{-1}$, respectivamente). Valores de $\mathrm{K}$ superiores $\left(417,218\right.$ e $\left.447 \mathrm{~kg} \mathrm{ha}^{-1}\right)$ foram obtidos por Boer et al. (2007), Carpim et al. (2008) e Torres \& Pereira (2008). Para o P, Boer et al. (2007), Carpim et al. (2008) e Torres et al. (2008) observaram valores semelhantes aos encontrados em Rio Verde (18, 22 e $25 \mathrm{~kg} \mathrm{ha}^{-1}$, respectivamente). Os resultados demonstram que 0 P. glaucum apresenta rápida emergência e crescimento até aos 60 DAS (florescimento) na safrinha, enquanto as espécies de Urochloa apresentaram significativo acúmulo de nutrientes em sua fitomassa mais tardiamente, sobretudo após o reinício das chuvas nos meses de setembro e outubro.
O uso da leguminosa C. cajan em consórcio com a U. ruziziensis não possibilitou incremento no acúmulo de N, em comparação ao cultivo da gramínea solteira.

Tabela 3. Relação $\mathrm{C} / \mathrm{N}$ e nutrientes acumulados $\left(\mathrm{kg} \mathrm{ha}^{-1}\right)$ nas fitomassas das plantas de cobertura semeadas em safrinha, após colheita da soja, safra 2007/2008, avaliados em seis épocas durante a entressafra, em Santo Antônio de Goiás, GO ${ }^{(1)}$.

\begin{tabular}{|c|c|c|c|c|c|c|}
\hline \multirow{2}{*}{$\begin{array}{l}\text { Planta de } \\
\text { cobertura }\end{array}$} & \multicolumn{6}{|c|}{ Época $(\mathrm{DAS})^{(2)}$} \\
\hline & 60 & 75 & 90 & 120 & 180 & 200 \\
\hline & \multicolumn{6}{|c|}{ Relação C/N } \\
\hline U. ruziziensis & $25 b$ & $27 b$ & $30 \mathrm{~b}$ & $34 \mathrm{ab}$ & $36 \mathrm{bc}$ & $34 \mathrm{c}$ \\
\hline U. brizantha & $24 b$ & $28 \mathrm{~b}$ & $29 b$ & $38 \mathrm{ab}$ & $43 a b c$ & $49 b$ \\
\hline P. glaucum $^{(3)}$ & $35 \mathrm{a}$ & $38 \mathrm{a}$ & $39 a$ & $40 \mathrm{a}$ & $47 \mathrm{ab}$ & $61 \mathrm{a}$ \\
\hline $\mathrm{UR}+\mathrm{CC}^{(4)}$ & $19 \mathrm{c}$ & $23 b$ & $26 b$ & $30 \mathrm{ab}$ & $33 \mathrm{c}$ & $32 \mathrm{c}$ \\
\hline Pousio & $13 \mathrm{~d}$ & $26 \mathrm{~b}$ & $27 \mathrm{~b}$ & $30 \mathrm{~b}$ & $50 \mathrm{a}$ & $31 \mathrm{c}$ \\
\hline \multirow[t]{2}{*}{ CV (\%) } & \multicolumn{6}{|c|}{12,01} \\
\hline & \multicolumn{6}{|c|}{$\mathrm{N}$} \\
\hline U. ruziziensis & $58,78 \mathrm{~b}$ & $140,86 a$ & $130,29 a$ & $113,95 b$ & $96,39 b$ & $155,95 \mathrm{a}$ \\
\hline U. brizantha & $52,05 \mathrm{~b}$ & $123,03 \mathrm{ab}$ & $144,72 \mathrm{a}$ & $171,72 \mathrm{a}$ & $137,56 a$ & $142,81 \mathrm{a}$ \\
\hline P. glaucum & $148,81 \mathrm{a}$ & $96,28 \mathrm{bc}$ & $61,56 b c$ & $60,84 \mathrm{c}$ & $44,53 \mathrm{c}$ & $38,13 b$ \\
\hline $\mathrm{UR}+\mathrm{CC}$ & $45,66 \mathrm{~b}$ & $85,57 \mathrm{c}$ & $88,76 \mathrm{~b}$ & $125,40 \mathrm{~b}$ & $95,73 b$ & $149,03 \mathrm{a}$ \\
\hline Pousio & $16,31 \mathrm{c}$ & $37,90 \mathrm{~d}$ & $35,00 \mathrm{c}$ & $34,02 \mathrm{~d}$ & $17,91 \mathrm{~d}$ & $35,84 \mathrm{~b}$ \\
\hline \multirow[t]{2}{*}{ CV (\%) } & \multicolumn{6}{|c|}{12,45} \\
\hline & \multicolumn{6}{|c|}{$\mathrm{P}$} \\
\hline U. ruziziensis & $8,63 b$ & $11,04 b$ & $9,77 b$ & $6,40 \mathrm{~b}$ & $9,77 \mathrm{a}$ & $12,45 \mathrm{a}$ \\
\hline$U$. brizantha & $8,06 b$ & $12,87 b$ & $10,59 b$ & $14,70 \mathrm{a}$ & $8,18 \mathrm{a}$ & $13,57 \mathrm{a}$ \\
\hline P. glaucum & $35,14 a$ & $27,17 \mathrm{a}$ & $13,52 \mathrm{a}$ & $13,30 \mathrm{a}$ & $8,13 \mathrm{a}$ & $6,98 b$ \\
\hline $\mathrm{UR}+\mathrm{CC}$ & $5,87 \mathrm{bc}$ & $7,99 \mathrm{bc}$ & $5,81 \mathrm{c}$ & $6,10 \mathrm{~b}$ & $9,56 \mathrm{a}$ & $13,56 \mathrm{a}$ \\
\hline Pousio & $2,77 \mathrm{c}$ & $3,37 \mathrm{c}$ & $3,24 \mathrm{c}$ & $4,32 \mathrm{~b}$ & $1,71 \mathrm{~b}$ & $4,14 \mathrm{~b}$ \\
\hline \multirow[t]{2}{*}{ CV (\%) } & \multicolumn{6}{|c|}{16,67} \\
\hline & \multicolumn{6}{|c|}{$\mathrm{K}$} \\
\hline U. ruziziensis & $40,38 b$ & $78,87 \mathrm{a}$ & $91,18 \mathrm{a}$ & $84,61 b$ & $60,45 b$ & $118,97 \mathrm{a}$ \\
\hline U. brizantha & $25,27 b$ & $88,89 a$ & $87,78 \mathrm{a}$ & $143,82 \mathrm{a}$ & $90,67 \mathrm{a}$ & $126,66 \mathrm{a}$ \\
\hline P. glaucum & $135,11 \mathrm{a}$ & $80,67 \mathrm{a}$ & $59,62 b$ & $55,59 \mathrm{bc}$ & $32,59 \mathrm{c}$ & $23,44 b$ \\
\hline $\mathrm{UR}+\mathrm{CC}$ & $27,07 b$ & $58,00 \mathrm{~b}$ & $59,42 b$ & $80,70 \mathrm{~b}$ & $58,03 \mathrm{~b}$ & $119,91 \mathrm{a}$ \\
\hline Pousio & $5,15 \mathrm{c}$ & $24,56 \mathrm{c}$ & $27,76 \mathrm{c}$ & $29,73 \mathrm{c}$ & $20,65 \mathrm{c}$ & $26,85 \mathrm{~b}$ \\
\hline \multirow[t]{2}{*}{ CV (\%) } & \multicolumn{6}{|c|}{15,18} \\
\hline & \multicolumn{6}{|c|}{$\mathrm{Ca}$} \\
\hline U. ruziziensis & $16,14 b$ & $31,94 \mathrm{a}$ & $53,57 \mathrm{a}$ & $39,79 a$ & $46,95 \mathrm{a}$ & $63,37 b$ \\
\hline U. brizantha & $8,29 b c$ & $27,94 a$ & $41,12 \mathrm{ab}$ & $39,61 \mathrm{a}$ & $52,12 \mathrm{a}$ & $91,29 a$ \\
\hline P. glaucum & $55,49 \mathrm{a}$ & $31,15 \mathrm{a}$ & $27,22 b$ & $22,77 b$ & $21,01 \mathrm{~b}$ & $17,67 \mathrm{c}$ \\
\hline $\mathrm{UR}+\mathrm{CC}$ & $9,08 \mathrm{bc}$ & $27,57 \mathrm{a}$ & $28,80 \mathrm{~b}$ & $32,61 \mathrm{ab}$ & $41,07 \mathrm{a}$ & $84,82 \mathrm{a}$ \\
\hline Pousio & $5,35 \mathrm{c}$ & $10,92 b$ & $30,21 \mathrm{~b}$ & $26,34 \mathrm{~b}$ & $20,26 \mathrm{~b}$ & $26,11 \mathrm{c}$ \\
\hline \multirow[t]{2}{*}{$\mathrm{CV}(\%)$} & \multicolumn{6}{|c|}{16,92} \\
\hline & \multicolumn{6}{|c|}{$\mathrm{Mg}$} \\
\hline U. ruziziensis & $6,39 b$ & $28,21 \mathrm{a}$ & $34,95 \mathrm{a}$ & $33,16 b$ & $26,56 b$ & $35,17 \mathrm{~b}$ \\
\hline U. brizantha & $6,22 b$ & $30,97 \mathrm{a}$ & $38,82 \mathrm{a}$ & $61,82 \mathrm{a}$ & $54,36 \mathrm{a}$ & $58,78 \mathrm{a}$ \\
\hline P. glaucum & $47,80 \mathrm{a}$ & $27,79 a$ & $18,63 b$ & $16,82 \mathrm{c}$ & $15,72 \mathrm{c}$ & $13,45 \mathrm{c}$ \\
\hline $\mathrm{UR}+\mathrm{CC}$ & $6,47 b$ & $19,40 \mathrm{a}$ & $20,59 b$ & $27,68 b$ & $24,46 b$ & $34,68 b$ \\
\hline Pousio & $1,85 \mathrm{~b}$ & $6,57 \mathrm{~b}$ & $7,52 \mathrm{c}$ & $12,12 \mathrm{c}$ & $7,63 \mathrm{~d}$ & $14,51 \mathrm{c}$ \\
\hline CV (\%) & \multicolumn{6}{|c|}{18,09} \\
\hline
\end{tabular}

${ }^{(1)}$ Médias seguidas de letras iguais, nas colunas, não diferem entre si pelo teste de Tukey, a 5\% de probabilidade. ${ }^{(2)}$ Dias após a semeadura das plantas de cobertura em Santo Antônio de Goiás, GO, 25/3/2008. (3)Dia da dessecação do P. glaucum no florescimento em Santo Antônio de Goiás, GO, 22/5/2008. ${ }^{(4)} \mathrm{UR}+\mathrm{CC}:$ U. ruziziensis + C. cajan. 
A elevada produção de fitomassa e a proporção de folhas/colmos na $U$. ruziziensis fez com que a quantidade de nitrogênio acumulada não se alterasse. Torres et al. (2008) observaram que a $U$. brizantha foi mais eficiente em acumular $\mathrm{N}$ do que o $C$. cajan, ao serem semeados no início do período chuvoso. Estudos com populações e espaçamentos de plantas entre as

Tabela 4. Relação C/N e nutrientes acumulados $\left(\mathrm{kg} \mathrm{ha}^{-1}\right)$ nas fitomassas das plantas de cobertura semeadas em safrinha, após colheita da soja, safra 2007/2008, avaliados em cinco épocas durante a entressafra, em Rio Verde, $\mathrm{GO}^{(1)}$.

\begin{tabular}{|c|c|c|c|c|c|}
\hline \multirow[t]{2}{*}{ Planta de cobertura } & \multicolumn{5}{|c|}{ Época $(\mathrm{DAS})^{(2)}$} \\
\hline & 60 & 75 & 90 & 120 & 180 \\
\hline & \multicolumn{5}{|c|}{ Relação C/N } \\
\hline U. ruziziensis & $20 \mathrm{~b}$ & $24 b$ & $40 \mathrm{bc}$ & $37 \mathrm{c}$ & $35 b$ \\
\hline P. glaucum $^{(3)}$ & $36 \mathrm{a}$ & $40 \mathrm{a}$ & $52 \mathrm{a}$ & $61 b$ & $67 \mathrm{a}$ \\
\hline $\mathrm{UR}+\mathrm{CC}^{(4)}$ & $21 b$ & $26 b$ & $34 c$ & $46 c$ & $45 b$ \\
\hline Pousio & $24 \mathrm{~b}$ & $26 \mathrm{~b}$ & $46 \mathrm{ab}$ & $71 \mathrm{a}$ & $58 \mathrm{a}$ \\
\hline \multirow[t]{2}{*}{ CV (\%) } & \multicolumn{5}{|c|}{11,22} \\
\hline & \multicolumn{5}{|c|}{$\mathrm{N}$} \\
\hline U. ruziziensis & $31,54 b$ & $54,56 \mathrm{ab}$ & $54,68 \mathrm{ab}$ & $55,78 \mathrm{a}$ & $116,13 \mathrm{a}$ \\
\hline P. glaucum & $70,00 \mathrm{a}$ & $59,02 \mathrm{a}$ & $45,65 \mathrm{ab}$ & $26,01 \mathrm{~b}$ & $13,54 \mathrm{c}$ \\
\hline $\mathrm{UR}+\mathrm{CC}$ & $27,64 b c$ & $41,24 b$ & $40,93 b$ & $31,88 \mathrm{~b}$ & $71,53 b$ \\
\hline Pousio & $22,95 \mathrm{c}$ & $49,83 \mathrm{ab}$ & $66,34 \mathrm{a}$ & $34,45 b$ & $29,40 \mathrm{c}$ \\
\hline \multirow[t]{2}{*}{ CV (\%) } & \multicolumn{5}{|c|}{18,10} \\
\hline & \multicolumn{5}{|c|}{$\mathrm{P}$} \\
\hline U. ruziziensis & $3,94 b$ & $7,25 b$ & $7,34 \mathrm{a}$ & $5,07 \mathrm{ab}$ & $10,41 \mathrm{a}$ \\
\hline P. glaucum & $11,57 \mathrm{a}$ & $10,02 \mathrm{a}$ & $6,68 b$ & 4,48ab & $2,33 b$ \\
\hline $\mathrm{UR}+\mathrm{CC}$ & $3,95 \mathrm{~b}$ & $6,11 b$ & $5,21 \mathrm{~b}$ & $3,83 b$ & $10,88 \mathrm{a}$ \\
\hline Pousio & $3,49 \mathrm{~b}$ & $7,79 \mathrm{~b}$ & $7,04 \mathrm{a}$ & $5,42 \mathrm{a}$ & $4,16 \mathrm{~b}$ \\
\hline \multirow[t]{2}{*}{ CV (\%) } & \multicolumn{5}{|c|}{14,14} \\
\hline & \multicolumn{5}{|c|}{ K } \\
\hline U. ruziziensis & $22,31 b$ & $31,67 b$ & $48,15 \mathrm{ab}$ & $33,20 \mathrm{~b}$ & $92,87 \mathrm{a}$ \\
\hline P. glaucum & $57,86 \mathrm{a}$ & $46,61 \mathrm{a}$ & $42,87 b$ & $21,71 \mathrm{c}$ & $11,21 \mathrm{~d}$ \\
\hline $\mathrm{UR}+\mathrm{CC}$ & $18,48 b$ & $23,93 \mathrm{c}$ & $33,60 \mathrm{c}$ & $24,71 \mathrm{c}$ & $51,59 \mathrm{~b}$ \\
\hline Pousio & $17,80 \mathrm{~b}$ & $31,44 b$ & $53,00 \mathrm{a}$ & $42,10 \mathrm{a}$ & $27,40 \mathrm{c}$ \\
\hline \multirow[t]{2}{*}{ CV (\%) } & \multicolumn{5}{|c|}{9,68} \\
\hline & \multicolumn{5}{|c|}{$\mathrm{Ca}$} \\
\hline U. ruziziensis & $9,20 \mathrm{~b}$ & $18,81 \mathrm{a}$ & $21,87 \mathrm{a}$ & $20,47 a$ & $53,80 \mathrm{a}$ \\
\hline P. glaucum & $22,60 \mathrm{a}$ & $21,09 \mathrm{a}$ & $19,23 \mathrm{a}$ & $12,72 b$ & $8,95 \mathrm{~d}$ \\
\hline $\mathrm{UR}+\mathrm{CC}$ & $8,64 b$ & $15,06 \mathrm{~b}$ & $14,17 b$ & $13,98 b$ & $31,98 b$ \\
\hline Pousio & $4,59 \mathrm{c}$ & $12,25 \mathrm{~b}$ & $14,49 \mathrm{~b}$ & $12,15 \mathrm{~b}$ & $21,53 \mathrm{c}$ \\
\hline \multirow[t]{2}{*}{ CV (\%) } & \multicolumn{5}{|c|}{7,83} \\
\hline & \multicolumn{5}{|c|}{$\mathrm{Mg}$} \\
\hline U. ruziziensis & $2,47 b$ & $5,00 \mathrm{~b}$ & $4,97 \mathrm{ab}$ & $10,21 \mathrm{a}$ & $11,59 \mathrm{a}$ \\
\hline P. glaucum & $7,32 \mathrm{a}$ & $6,77 \mathrm{a}$ & $5,59 \mathrm{a}$ & $4,34 \mathrm{c}$ & $1,82 \mathrm{~d}$ \\
\hline $\mathrm{UR}+\mathrm{CC}$ & $1,83 \mathrm{c}$ & $3,52 \mathrm{c}$ & $3,85 \mathrm{bc}$ & $4,19 \mathrm{c}$ & $8,45 b$ \\
\hline Pousio & $1,65 \mathrm{c}$ & $2,33 \mathrm{~d}$ & $3,27 \mathrm{c}$ & $6,43 \mathrm{~b}$ & $2,89 \mathrm{c}$ \\
\hline CV (\%) & \multicolumn{5}{|c|}{10,81} \\
\hline
\end{tabular}

${ }^{(1)}$ Médias seguidas de letras iguais nas colunas não diferem entre si pelo teste de Tukey, a $5 \%$ de probabilidade. ${ }^{(2)}$ Dias após a semeadura das plantas de cobertura em Rio Verde, GO, 10/4/2008. ${ }^{(3)}$ Dia da dessecação do P. glaucum no florescimento em Rio Verde, GO, 12/6/2008. ${ }^{(4)} \mathrm{UR}+\mathrm{CC}:$ U. ruziziensis + C. cajan. espécies $U$. ruziziensis e C. cajan são necessários para avaliar o melhor arranjo para seus usos na produção de fitomassa e no acúmulo de nutrientes para o sistema plantio direto.

De acordo com resultados de Reis et al. (2001), os elevados valores de $\mathrm{N}$ acumulado pelas fitomassas de P. glaucum, U. brizantha e U. ruziziensis podem ter sido influenciados pelas propriedades dessas espécies de se associarem a bactérias fixadoras de nitrogênio, com predominância da Herbaspirillum e da Azospirillum. Segundo os autores, esse processo pode contribuir com mais de 40 e $20 \%$ do nitrogênio acumulado nas fitomassas de P. glaucum e das espécies de Urochloa, respectivamente.

Os maiores valores no acúmulo de nutrientes em Santo Antônio de Goiás ocorreram em razão da antecedência na semeadura das plantas de cobertura, da fertilidade do solo mais favorável à disponibilidade de nutrientes às plantas e da maior precipitação nos meses de maio e agosto, que proporcionaram melhor estabelecimento e rebrota das plantas de cobertura.

As maiores taxas de liberação de nutrientes foram observadas no P. glaucum: $\mathrm{P}, \mathrm{K}$ e $\mathrm{N}$ seguidos de $\mathrm{Mg}$ e Ca (Tabela 5). Boer et al. (2007), que trabalharam com o ADR 500, e Torres et al. (2008) e Torres \& Pereira (2008), que trabalharam com o P. americanum sin typhoides, encontraram valores $\mathrm{T}^{1} / 2$ vida de $\mathrm{P}, \mathrm{N}$ e $\mathrm{K}$ superiores ao deste estudo (210, 90 e 110 dias após a dessecação do milheto, respectivamente). A baixa meia-vida do $\mathrm{K}$ está relacionada ao fato de esse elemento não estar associado a nenhum componente estrutural da célula (Torres et al., 2005). Os resultados mostraram que a liberação de nutrientes do P. glaucum ocorreu de forma mais intensa nos primeiros 60 dias após o manejo, seguido de uma fase mais resistente à decomposição. Segundo Aita \& Giacomini (2003), os resíduos de plantas de cobertura apresentam frações de decomposição mais rápida ( $\mathrm{N}$ e $\mathrm{C}$ da fração solúvel em água) e outra parte mais resistente aos agentes decompositores (lignina, e $\mathrm{N}$ e $\mathrm{C}$ da fração não solúvel em água).

Há baixa taxa de liberação do cálcio porque este nutriente está presente em constituintes estruturais da célula, como a parede celular, e é cofator de algumas enzimas envolvidas na respiração das plantas, o que dificulta sua mineralização e liberação ao solo (Boer et al., 2007). 
As variações na velocidade de liberação dos nutrientes, observadas neste trabalho e na literatura, podem ser explicadas pelas diferenças nas condições climáticas (precipitação e temperatura), e pelo uso ou não de sacolas de náilon ("litter bags"), em que a fitomassa coletada é triturada e armazenada na superfície do solo.

Em relação ao acúmulo de nutrientes pelas espécies $U$. brizantha, U. ruziziensis e U. ruziziensis $+C$. cajan, em Santo Antônio de Goiás (Tabela 5), a U. ruziziensis + C. cajan apresentou acúmulo linear de $\mathrm{P}, \mathrm{Ca}$ e $\mathrm{Mg}$, enquanto a $U$. brizantha apresentou maiores taxas no acúmulo de $\mathrm{Ca}$ e $\mathrm{Mg}$ entre 45 e 120 DAS. Os elevados acúmulos de nutrientes apresentados pela $U$. brizantha ocorreram por causa da resistência satisfatória da espécie ao deficit hídrico. Em Rio Verde, a U. ruziziensis, a $U$. ruziziensis + C. cajan e o pousio apresentaram crescimento linear no acúmulo de nutrientes. A ocorrência de rebrota dessas espécies, logo após o início das chuvas de verão, possibilitou incrementos em fitomassa e nutrientes acumulados em suas partes

Tabela 5. Equação de regressão de acúmulo $^{(1)}$ e liberação(2) para N, P, K, Ca e Mg, e tempo de meia-vida ( $\left.\mathrm{T}^{1} / 2\right)$ observada na fitomassa seca das plantas de cobertura em safrinha, avaliadas em cinco épocas em Santo Antônio de Goiás, GO e em Rio Verde, GO.

\begin{tabular}{|c|c|c|c|}
\hline $\begin{array}{l}\text { Planta de } \\
\text { cobertura }\end{array}$ & Equação de acúmulo ou liberação & $\mathrm{R}^{2}$ & $\begin{array}{c}\mathrm{T}^{1} / 2 \\
\text { (dias) } \\
\end{array}$ \\
\hline & \multicolumn{3}{|c|}{ Santo Antonio de Goiás, GO } \\
\hline P. glaucum & $\mathrm{N}_{\mathrm{L}}=253,68 \exp (-0,0116 \mathrm{t})$ & $0,80 * *$ & 60 \\
\hline $\mathrm{UR}+\mathrm{CC}^{(3)}$ & $P_{a}=2,80+0,0443 x$ & $0,70^{*}$ & - \\
\hline P. glaucum & $\mathrm{P}_{\mathrm{L}}=82,83 \exp (-0,0155 \mathrm{t})$ & $0,88^{* *}$ & 45 \\
\hline P. glaucum & $K_{L}=273,41 \exp (-0,0141 t)$ & $0,87 * *$ & 49 \\
\hline U. brizantha & $\mathrm{Ca}_{\mathrm{a}}=-9,55+0,4423 \mathrm{x}$ & $0,81^{*}$ & - \\
\hline P. glaucum & $\mathrm{Ca}_{\mathrm{L}}=73,46 \exp (-0,0085 \mathrm{t})$ & $0,69^{*}$ & 82 \\
\hline U. brizantha & $\mathrm{Mg}_{\mathrm{a}}=6,55+0,2930 \mathrm{x}$ & $0,63 *$ & - \\
\hline $\mathrm{UR}+\mathrm{CC}$ & $\mathrm{Mg}_{\mathrm{a}}=5,74+0,1363 \mathrm{x}$ & $0,68^{*}$ & - \\
\hline \multirow[t]{2}{*}{ P. glaucum } & $\mathrm{Mg}_{\mathrm{L}}=75,90 \exp (-0,011 \mathrm{t})$ & $0,69^{*}$ & 63 \\
\hline & \multicolumn{3}{|c|}{ Rio verde, GO } \\
\hline U. ruziziensis & $\mathrm{N}_{\mathrm{a}}=-3,61+0,6301 \mathrm{x}$ & $0,89 *$ & - \\
\hline P. glaucum & $\mathrm{N}_{\mathrm{L}}=71,15 \exp (-0,015 \mathrm{t})$ & $0,99 * *$ & 46 \\
\hline P. glaucum & $P_{L}=29,39 \exp (-0,0153 t)$ & $0,98 * *$ & 45 \\
\hline U. ruziziensis & $\mathrm{K}_{\mathrm{a}}=-10,21+0,5319 \mathrm{x}$ & $0,81^{*}$ & - \\
\hline P. glaucum & $\mathrm{K}_{\mathrm{L}}=137,24 \exp (-0,0142 \mathrm{t})$ & $0,98 * *$ & 48 \\
\hline U. ruziziensis & $\mathrm{Ca}_{\mathrm{a}}=-10,59+0,3373 \mathrm{x}$ & $0,89^{*}$ & - \\
\hline $\mathrm{UR}+\mathrm{CC}$ & $\mathrm{Ca}_{\mathrm{a}}=-1,38+0,1728 \mathrm{x}$ & $0,85^{*}$ & - \\
\hline P. glaucum & $\mathrm{Ca}_{\mathrm{L}}=38,35 \exp (-0,0083 \mathrm{t})$ & $0,97 * *$ & 83 \\
\hline U. ruziziensis & $\mathrm{Mg}_{\mathrm{a}}=-1,16+0,0763 \mathrm{x}$ & $0,87^{*}$ & - \\
\hline $\mathrm{UR}+\mathrm{CC}$ & $\mathrm{Mg}_{\mathrm{a}}=-0,89+0,0501 \mathrm{x}$ & $0,94 * *$ & - \\
\hline P. glaucum & $\mathrm{Mg}_{\mathrm{L}}=14,19 \exp (-0,0104 \mathrm{t})$ & $0,98 * *$ & 67 \\
\hline
\end{tabular}

${ }^{(1)} \mathrm{P}_{\mathrm{a}}=\mathrm{Po}+\mathrm{ax} \cdot{ }^{\left({ }^{2}\right)} \mathrm{P}_{\mathrm{L}}=\mathrm{Po} \exp (-\mathrm{kt}) \cdot{ }^{(3)} \mathrm{UR}+\mathrm{CC}:$ U. ruziziensis + C. cajan.

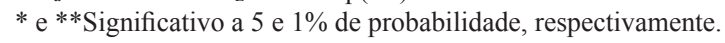

aéreas, ao equiparar-se aos valores acumulados pelo $P$. glaucum aos 60 DAS (florescimento).

\section{Conclusões}

1. O Pennisetum glaucum destaca-se na produção de fitomassa, no acúmulo e na liberação dos nutrientes $\mathrm{P}$, $\mathrm{K}$ e N, no início da entressafra.

2. A fitomassa remanescente do P. glaucum ao final da entressafra é insuficiente para promover a cobertura adequada do solo para a cultura sucessora em plantio direto.

3. As espécies Urochloa brizantha, U. ruziziensis e o consórcio U. ruziziensis + Cajanus cajan apresentam elevado acúmulo de fitomassa e nutrientes no final da entressafra.

4. A semeadura precoce e a ocorrência de chuvas em abril e maio contribuem para o desenvolvimento das plantas de cobertura, na entressafra.

\section{Agradecimentos}

À Fundação Agricultura Sustentável e à Embrapa Arroz e Feijão, pelo apoio financeiro; e à Coordenação de Aperfeiçoamento de Pessoal de Nível Superior, pela concessão de bolsa de Doutorado.

\section{Referências}

AITA, C.; GIACOMINI, J. Decomposição e liberação de nitrogênio de resíduos culturais de plantas de cobertura do solo solteiras e consorciadas. Revista Brasileira de Ciência do Solo, v.27, p.601612, 2003.

AMABILE, R.F.; FANCELLI, A.L.; CARVALHO, A.M. Comportamento de espécies de adubos verdes em diferentes épocas de semeadura e espaçamentos na região dos cerrados. Pesquisa Agropecuária Brasileira, v.35, p.47-54, 2000.

BOER, C.A.; ASSIS, R.L.; SILVA, G.P.; BRAZ, A.J.B.P.; BARROSO, A.L.L.; CARGNELUTTI FILHO, A.; PIRES, F.R. Ciclagem de nutrientes por plantas de cobertura na entressafra em um solo de cerrado. Pesquisa Agropecuária Brasileira, v.42, p.1269-1276, 2007.

CANTARELLA, H.; QUAGGIO, H.C.; RAIJ, B.V. Determinação da Matéria Orgânica. In: RAIJ, B.V.; ANDRADE, J.C.; CANTERELLA, H.; QUAGGIO, J.A. (Ed). Análise química para avaliação da fertilidade de solos tropicais. Campinas: Instituto Agronômico de Campinas, 2001. p.173-188.

CARPIM, L.; ASSIS, R.L.; BRAZ, A.J.B.P.; SILVA, G.P.; PIRES, F.R.; PEREIRA, V.C.; GOMES, G.V.; SILVA, A.G. Liberação de nutrientes pela palhada de milheto em diferentes estádios fenológicos. Revista Brasileira de Ciência do Solo, v.32, p.28132819, 2008. 
COMPANHIA NACIONAL DE ABASTECIMENTO. $\mathbf{1 1}^{\mathbf{0}}$ levantamento da produção de grãos: safra 2008/09. Brasília: CONAB, 2009. Disponível em: <www.conab.gov.br>. Acesso em: 27 de mar. 2009.

CRUSCIOL, C.A.C.; COTTICA, R.L.; LIMA, E.V.; ANDREOTTI, M.; MORO, E.; MARCON, E. Persistência de palhada e liberação de nutrientes do nabo forrageiro no plantio direto. Pesquisa Agropecuária Brasileira, v.40, p.161-168, 2005.

CRUSCIOL, C.A.C.; SORATTO, R.P. Nutrição e produtividade do amendoim em sucessão ao cultivo de plantas de cobertura no sistema plantio direto. Pesquisa Agropecuária Brasileira, v.42, p.1553-1560, 2007.

GAMA-RODRIGUES, A.C.; GAMA-RODRIGUES, E.F.; BRITO, E.C. Decomposição e liberação de nutrientes de resíduos culturais de plantas de cobertura em Argissolo Vermelho-Amarelo na região Noroeste Fluminense (RJ). Revista Brasileira de Ciência do Solo, v.31, p.1421-1428, 2007.

GIACOMINI, S.J.; AITA, C.; HUBNER, A.P.; LUNKES, A.; GUIDINI, E.; AMARAL, E.B. Liberação de fósforo e potássio durante a decomposição de resíduos culturais em plantio direto. Pesquisa Agropecuária Brasileira, v.38, p.1097-1104, 2003.

HENRIKSEN, I.; MICHELSEN, A.; SCHLONVOIGT, A. Tree species selection and soil tillage in alley cropping systems with Phaseolus vulgaris L. in a humid premontane climate: biomass production, nutrient cycling and crop responses. Plant and Soil, v.240, p.145-159, 2002.

NOGUEIRA, A.R. de A. MATOS, A. de O.; CARMO, C.A.F. de S. do; SILVA, D.J.; MONTEIRO, F.L.; SOUZA, G.B. de; PITTA, G.V.E.; CARLOS, G.M.; OLIVEIRA, H. de; COMASTRI FILHO, J.A.; MIYAZAWA, M.; OLIVEIRA NETO, W. de. Tecido vegetal. In: NOGUEIRA, A.R. de A.; SOUZA, G.B. de (Ed). Manual de laboratórios: solo, água, nutrição vegetal, nutrição animal e alimentos. São Carlos: Embrapa Pecuária Sudoeste, 2005. p.145-199.

PACHECO, L.P.; PIRES, F.R.; MONTEIRO, F.P.; PROCOPIO, S.O.; ASSIS, R.L.; CARMO, M.L.; PETTER, F.A. Desempenho de plantas de cobertura em sobressemeadura na cultura da soja. Pesquisa Agropecuária Brasileira, v.43, p.815-823, 2008.

PAUL, E.A.; CLARK, F.E. Soil microbiology and chemistry. San Diego: Academic Press, 1989. 275p.
PIRES, F.R.; ASSIS, R.L.; PROCÓPIO, S.O.; SILVA, G.P.; MORAES, L.L.; RUDOVALHO, M.C.; BOER, C.A. Manejo de plantas de cobertura antecessora à cultura da soja em plantio direto. Revista Ceres, v.55, p.94-101, 2008.

PORTES, T.A.; CARVALHO, S.I.C.; OLIVEIRA, I.P.; KLUTHCOUSKI, J. Análise do crescimento de uma cultivar de braquiária em cultivo solteiro e consorciado com cereais. Pesquisa Agropecuária Brasileira, v.35, p.1349-1358, 2000.

PRIOR, S.A.; TORBERT, H.A.; RUNION, G.B.; ROGERS, $\mathrm{H}$. Elevated atmospheric $\mathrm{CO} 2$ in agroecosystems: residue decomposition in the field. Environmental Management, v.33, p.344-354, 2004.

REIS, V.M.; REIS JUNIOR, F.B.; QUESADA, D.M.; OLIVEIRA, O.C.A.; ALVES, B.J.R.; URQUIAGA, S. ; BODDEY, R.M. Biological nitrogen fixation associated with tropical pasture grasses. Australian Journal of Plant Physiology, v.28, p.837844, 2001.

SANTOS, H.G. dos; JACOMINE, P.K.T.; ANJOS, L.H.C. dos; OLIVEIRA, V.A. de; OLIVEIRA, J.B. de; COELHO, M.R.; LUMBRERAS, J.F.; CUNHA, T.J.F. (Ed.). Sistema brasileiro de classificação de solos. 2.ed. Rio de Janeiro: Embrapa Solos, 2006. 306p.

TIMOSSI, P.C.; DURIGAN, J.C.; LEITE, G.J. Formação de palhada por braquiárias para adoção do sistema plantio direto. Bragantia, v.66, p.617-622, 2007.

TORRES, J.L.R.; PEREIRA, M.G. Dinâmica do potássio nos resíduos vegetais de plantas de cobertura no cerrado. Revista Brasileira de Ciência do Solo, v.32, p.1609-1618, 2008.

TORRES, J.L.R.; PEREIRA, M.G.; ANDRIOLI, I.; POLIDORO, J.C.; FABIAN, A.J. Decomposição e liberação de nitrogênio de resíduos culturais de plantas de cobertura em um solo de cerrado. Revista Brasileira de Ciência do Solo, v.29, p.609-618, 2005.

TORRES, J.L.R.; PEREIRA, M.G.; FABIAN, A.J. Produção de fitomassa por plantas de cobertura e mineralização de seus resíduos em plantio direto. Pesquisa Agropecuária Brasileira, v.43, p.421428, 2008.

WIEDER, R.K.; LANG, G.E. A critique of the analytical methods used in examining decomposition data obtained from litter bags. Ecology, v.63, p.1636-1642, 1982. 